\title{
COMPETENCIAS Y LITERATURA: UNA ODISEA
}

\author{
Diego José Martínez Gayón*
}

\section{Resumen}

En el siguiente ensayo sugiero algunas dificultades que afectan a la enseñanza de la literatura a nivel bachillerato, desde la problemática del alumno, el docente y el entorno escolar; puesto que, es en la etapa previa a la vida universitaria donde un importante número de lectores latentes pierde interés en la literatura por encontrarla inútil. La obligatoriedad, los preconceptos, la falta de sensibilidad literaria y la ignorancia condicionan el acercamiento a los libros. Al final, propongo un ejemplo que busca vincular una acercamiento a la enseñanza de la literatura por competencias.

\section{Abstract}

In the next essay I suggest some difficulties that affect the teaching of literature to high school level, since the problem of students, teachers and the school environment. It is in the pre-university life where a significant number of potential readers loses their interest in literature because they find it useless. The requirement, the preconceptions, lack of sensitivity and literary ignorance condition for rapprochement with the books. At the end, I propose an example that seeks to link an approach to the teaching of literature competency.

PALABRAS CLAVE: Enseñanza bachillerato, literatura, competencias, propuesta.

* Autor de los libros: Cantos para esparcir la semilla (Fondo Editorial Tierra Adentro, 2000), Volverás al odio (La Rana / Instituto de Cultura de Guanajuato, 2003), Nuevos salvajismos: la perversión civilizada (CECUT, 2005), El camino del té (Mondadori, 2005), Los oficios de la transparencia (Libros del Umbral, 2007) y Un cuerpo (451editores, 2008). Su obra ha sido distinguida con los siguientes premios nacionales: Carlos Pellicer para obra publicada (2000), Efraín Huerta en poesía (2002), Abigael Bohórquez en Ensayo (2004) y Enriqueta Ochoa en poesía (2006). Docente de la Escuela de Ciencias Humanas de la Universidad La Salle Pachuca.djpoeta@yahoo.com 
Conozco a mucha gente exitosa que prácticamente nunca ha leído un libro, puesto que la lectura es irrelevante para el ejercicio de su profesión. ¿Para qué puede servir un poema, una novela, un ensayo literario? Pragmáticamente hablando para nada, aunque el poeta William Carlos Wiliams tiene otra respuesta: "Es difícil / sacar noticias de un poema / pero los hombres todos los días / mueren miserablemente / por no tener aquello que / tienen los poemas". La idea que contempla a la literatura como una pérdida de tiempo no sólo parece dominar el terreno laboral, también el académico, ya que la materia de literatura, por su aparente inutilidad, no goza del prestigio que tiene la matemática o la física. Algunos padres de familia sienten orgullo cuando sus hijos destacan en las materias de prestigio, y les preocupa en menor grado si sus vástagos apenas aprueban literatura: "bueno, pero es literatura, malo que reprueben ciencias". Extrañamente, de antiguo (y en otros países) la materia de literatura servía para enseñar lengua, historia, cultura e incluso geografía.

La lectura, aun cuando forma parte de la agenda política en materia cultural, sigue siendo un páramo inhóspito para un considerable número de mexicanos, incluso para docentes que ostentan sendos títulos pero cuya relación con los libros fue meramente técnica e informativa. Sin duda, uno de los periodos donde mayoritariamente se pierden lectores es en la etapa de escolarización correspondiente al bachillerato. Habría que preguntarse en qué momento y por qué se pierde el gusto por los libros, ya que los niños, sobre todo los más pequeños, siguen entusiasmándose gozosamente frente a ellos (incluso existiendo internet, televisión por cable y otros medios audiovisuales); para un pequeño que tiene acceso a los libros, nada puede compararse a la relación que desarrolla con estos objetos mágicos, una relación (hay que decirlo) desinteresada. Lo cierto es que en algún lugar del viaje, la lectura desinteresada es mal vista por la obligatoriedad y el requisito. El niño que al aprender a leer, padeció la lectura como una presión para ser "competente" en la escuela, involuntariamente pierde el interés por futuros aprendizajes e inicia su camino de deserción, no sólo en la lectura sino para el aprendizaje, al respecto enfatizan Bruno Bettelheim y Karen Zelan en Aprender a leer: "el aprendizaje de la lectura con frecuencia sella el destino, de una vez por todas, de su carrera académica". Esta situación suele ser frecuente a lo largo de la escolarización, razón por la cual, muchos jóvenes de bachillerato arriban a la materia de literatura convencidos que la lectura no es importante y que carece por completo de interés. Este rechazo es alimentado por una concepción utilitaria y meritoria de la educación que se aboca a repetir que sólo es preciso aprender el conocimiento útil. 
Dice Rodolfo Castro en La intuición de leer, la intención de narrar: "nos enseñan a que el tiempo es oro, que el ocio es nocivo, que lo que no reditúa bienes materiales es una pérdida de tiempo, que el progreso y la tecnología son razón de la vida y que la eficiencia es la mayor de las virtudes humanas; y luego de tanto pragmatismo y superficialidad nos recomiendan que disfrutemos la lectura. ¡Socorro!".

Entre los factores que dificultan la enseñanza de la literatura, desde la perspectiva del alumno de bachillerato, también debo mencionar la sobre-estimulación producida por la alienación tecnólogica de nuestro tiempo, así como por los rezagos culturales (generados tanto en el ámbito familiar como en la escuela) que no permiten la conexión adecuada de los contenidos, la hipertrofia de la información a través de los media (Internet) que saturan la selectividad, el empobrecimiento del lenguaje promovido por prácticas como los chats y los mensajes por celular, el aislamiento recurrente por el uso de lpods y otros dispositivos que derivan en una bajísima capacidad de concentración típica del homozapping.

Cierto, pero estos factores también afectan al docente, a los que hay que sumar: por una parte, la predisposición a los gustos e intereses de los alumnos (las historietas, la novela gráfica, las letras de sus grupos musicales favoritos, los blogs); y por otra, una concepción dogmática de la lectura, falta de actualización en el acontecer literario actual, escasez de lecturas que son suplidas por manuales. Aunado a las dificultades del entorno escolar: los programas de literatura pretenden abarcar en un semestre una visión histórica de la literatura universal, la cual reduce la experiencia literaria a una errática idea del vano memorizar datos generales sobre autores, obras y periodos; así como la simulación docente (cuando el maestro supone tener los conocimientos que enseña) que conlleva a la evasión de temas y lecturas por considerarlos difíciles y áridos (difíciles, claro está, para el docente; pero, que subestima las capacidad del alumno).

La vía motivacional para la lectura en el aula es partir del convencimiento y el agrado genuino del docente respecto a las obras que enseña en clase, así como el incrementar su cultura literaria para que ésta le brinde un dominio real sobre los contenidos de clase, y el recurrir a métodos didácticos que permitan al alumno acceder no sólo a la información literaria, sino a un campo mayor donde desarrolle habilidades como la expresión oral y escrita, la comunicación no verbal, el lenguaje visual, la comprensión y la imaginación. Puesto que en la imaginación se encuentran las principales aportaciones de la literatura (aportaciones intangibles): un poema, una novela, un ensayo contribuyen a la generación de preguntas sobre la condición humana. 
Preguntas que nos conducen al reconocimiento de nuestra propia condición y conciencia (aportación ética), preguntas sobre la condición del otro (empatía, función social), preguntas que nos permiten detenernos a pensar antes de actuar impulsivamente (dilación reguladora). Aunque la literatura no es moralizante, catapulta al individuo a vivir la eticidad y a reconocer su identidad, aunque no depende de tal o cual literatura sino de la relación entre el lector y el libro. Por lo tanto, no es suficiente poseer las categorías críticas para enseñar a analizar el contenido de una obra, el docente de literatura requiere una sensibilidad literaria sustentada en su formación cultural, de tal modo, que la exposición de una lectura abarque niveles de textualidad (lo que dice el texto, el lenguaje que utiliza y los aspectos retóricos en que se sustenta), contextualidad (tanto de la obra como del autor) e intertextualidad (aquellas obras con las que se encuentra o dialoga en la historia de la literatura). Sin duda, al abrir el espectro de las competencias relacionadas con el conocimiento literario, el maestro encontrará una forma de aproximar a los alumnos a la experiencia de la literatura, aunque como bien advirtió Warren $\mathrm{G}$. Cutts en La enseñanza moderna de la lectura:

Enseñar las técnicas de análisis de la palabra -incluso las diversas capacidades de comprensión- tienen escaso valor si el niño no experimenta el deseo de leer. Podría decirse aun que éste, ya sea por placer o por obtener información, puede conducir al dominio de la habilidad necesaria.

Entre las competencias básicas que se contemplan dentro del campo del lenguaje, destacarían: el dominio del idioma; la expresión coherente, clara y fluida; expresión escrita; comprensión de textos; aplicación de técnicas de investigación; interpretación de distintos lenguajes; análisis e interpretación del sentido literario; desarrollo de la creatividad; adquisición del hábito de la lectura por interés personal.

La relación entre expresión y dominio de la lengua oral y escrita con la literatura es obvia, así como la comprensión, el análisis y la interpretación de textos. Acaso la intención creativa y participativa como medio para acceder a dicho análisis y a tal interpretación es la que permitiría el desarrollo de habilidades distintas, puesto que, las otras competencias, mientras no clarifiquen con exactitud en dónde radica la diferencia, siguen comprendiendo el aprendizaje en un único y mismo sentido. Por otra parte, cabe señalar que el interés es excluido del ámbito de estudio, y relegado a título personal; esto, como ya expuse, para efectos de la enseñanza de la literatura va en detrimento, no sólo del gusto y el deseo por leer sino de la adquisición del hábito de la lectura. Lo digo con Juan Domingo Argüelles, quien puntualiza en su libro ¿Qué leen los que no leen?: "Por eso se esfuerzan tanto los métodos pedagógicos en 'orientar' el gusto, en disciplinar el hábito, en domesticar la pasión. 
Y no puede haber mayor contradicción que pretender que la gente lea como costumbre con estos métodos, cuando la lectura en sí misma parte de una disposición natural de caos, de indisciplina, de anarquía, de libertad".

La idea de mediador educativo en literatura debe aspirar a convertir a sus alumnos en lectores capaces de disfrutar, de cuestionar, de sensibilizarse y de concebir una idea del mundo. El reto del mediador educativo es crear las condiciones para que el educando descubra que la lectura es un actividad grata y significativa. Considero que el enfoque por competencias debe servir para desarrollar los procesos de enseñanza y de aprendizaje, no para condicionar la educación. En literatura no sólo intervienen las habilidades analíticas y lingüísticas; el interés y la apreciación resultan esenciales para su transmisión y para la disposición a otras formas de aprendizaje y a otras habilidades. Vuelvo a Bettelheim y a Zelan: "Si, en lugar de concentrarse en desarrollar las habilidades lectoras, los esfuerzos pedagógicos se concentraran desde un principio en desarrollar el deseo de formarse -en esencia, una actitud interior ante la lectura-, entonces el resultado final podría ser que el calificativo 'instruido' cabría aplicarlo a un segmento mucho mayor de la población adulta".

La manera en que el maestro enseña literatura, sobre todo a nivel bachillerato, resulta definitiva para desarrollar en los alumnos un interés auténtico por el conocimiento y por los libros, dicho interés se verá reflejado en la actitud con la cual iniciará y transcurrirá su vida universitaria, etapa en la que debería poseer el deseo de formarse como persona en la profesión que ha elegido.

La lectura no asegura el éxito, ni necesariamente nos convierte en mejores personas; en cambio, puede (si el lector lo permite) ampliar nuestra percepción, incrementar nuestra sensibilidad y brindarnos una manera distinta de imaginarnos y de imaginar a los otros.

Descripción de una propuesta que promueva competencias en la enseñanza de la literatura

La odisea de Homero puede servir para integrar un conjunto de temas, campos y competencias que contribuyan al desarrollo de habilidades como el pensamiento analítico, la expresión oral y escrita, la creatividad y la imaginación capaces de despertar el interés del alumno por la lectura y de proporcionarle un conocimiento más integral de la cultura, de la literatura griega y de sí mismos como personas. 
1. El docente induce al grupo mediante la lectura de un pasaje de la obra de Homero, a fin de ubicar y especificar el tema: Los viajes de Odiseo. Explicará quién es Odiseo (Ulises), quién fue Homero y cuál es la importancia de su obra. La odisea no es un poema lineal, puesto que sigue la estructura del mito. La primera circunferencia del viaje la traza Telémaco, quien va en busca del relato que le revele el destino de su padre; dentro de esta línea se abren los relatos de Menelao y del viejo Nestor; por el centro de la espiral narrativa, Odiseo cuenta la Odisea a su anfitrión, Alcinoo, rey de los Feacios. El sentimiento que atraviesa el poema es la nostalgia: el dolor producido por la sensación de la lejanía que se traduce en añoranza, deseo por regresar (sentimiento y situación completamente modernos).

2. Para la comprensión de La odisea son necesarios ciertos conocimientos previos que el docente deberá reforzar: a) teoría de los géneros literarios para identificar la tradición épica, señalar que se trata de una obra en verso; b) Genealogía homérica (principales mitos que se vinculan con el poema); c) Ubicación de La odisea frente a La lliada y al sitio de Troya (pues fue al ingenioso Odiseo a quien se le ocurrió semejante disparate). Para esta exposición se sugiere utilizar mapas mentales.

3. Actividad preparada: el docente divide al grupo en equipos y les reparte tarjetas en cuyo frente indica alguna de las aventuras de La Odisea, por ejemplo: La huída del país de los lotófagos, La isla de los cíclopes, Los vientos de Eolo, El país de los lestrigones, La isla de Ea, El descenso al Hades, La isla de las sirenas, la gruta de Escila y Caribdis, La furia de Helios por sus rebaños, La isla de Calipso, La isla de los Feacios. En el reverso de la tarjeta se incluirá alguna frase representativa de estos pasajes, por ejemplo: "Llegamos a la isla de Eolia, donde vivía Eolo, dilecto de los dioses inmortales. Es una isla flotante, rodeada de un muro de bronce indestructible". Tras leer la tarjeta, los alumnos describirán de forma oral a sus compañeros de equipo, cómo imaginan estos lugares y qué imaginan que le sucedió a Odiseo, después escribirán un texto común que integre las distintas concepciones.

4. El maestro describe la trayectoria de Odiseo y lee fragmentos representativos de los distintos viajes.

5. Los alumnos trazan en el pizarrón una línea cronológica donde ubicar las tarjetas y donde apuntar aspectos relevantes de las aventuras, por ejemplo: ¿qué es un cíclope?: criatura con un solo ojo que vive aislado en cavernas y grutas, dedicándose a pastorear sus rebaños. ¿Quién es Circe?: la diosa que transformaba a los hombres en cerdos, pero que amó a Odiseo, a quien le reveló cómo descender al Hades. ¿Qué son la sirenas, cuyo canto precipita a los hombres a la locura?, dice Italo Calvino que las sirenas en realidad están 
cantando la Odisea. ¿Quiénes son Escila y Caribdis?: monstruosas compañeras, Escila fue hermosa, pero Circe la convirtió en un perro con seis cabezas y Caribdis posee una voracidad que la obliga a engullir el mar y a vomitarlo.

6. Alguna tarea puede ser la representación gráfica (dibujo, collage, fotografía) de aquel lugar que les pareciera más atractivo, incluyendo a las criaturas fantásticas y a los personajes implicados, leyendo en casa el capítulo correspondiente.

7. Lectura grupal de alguno de los cantos finales de La Odisea.

8. El maestro analiza el mito del regreso y el sentimiento de la nostalgia como temas recurrentes en la literatura, el cine y el arte. Se puede servir de ejemplos contemporáneos como Ulises de Joyce, Omeros de Walcott, Ítaca de Kavafis o Sobre un verso ajeno de Seferis.

Algunos recursos como proyección de imágenes sobre Grecia o música incidental, pueden contribuir a la clase y motivar el trabajo en el aula. Para la realización de esta planeación se requiere un mínimo de 4 horas, una buena disposición para hacer el material, seleccionar los pasajes y elaborar los contenidos.

Pero más allá de los recursos técnicos y de las dinámicas, la única forma para que el alumno se apropie del conocimiento de La Odisea, motivándose a leer y a adquirir el deseo de leer ésta y otras obras, depende de la relación que el maestro tenga con la lectura, si su gusto no es auténtico fracasará con o sin competencias, con o sin recursos, pues es imposible interesar a alguien en algo que no nos interesa a nosotros mismos.

Hace unos meses, Derek Walcott, Premio Nobel de literatura en 1992, dio una lectura en México, donde explicó la universalización de ciertos temas como el viaje y el regreso, la nostalgia y el emprendimiento, temas que indistintamente ha tocado la literatura, su argumento era que, de alguna manera la tradición homérica sigue presente, puesto que cada vez que alguien escribe o lee un poema, está realizando un viaje en busca de sí mismo, de aquello que ama, teme, añora o espera, dicho viaje es una odisea

\section{Fuentes de consulta}

ARGÜELLES, J. D. (2003) ¿Qué leen los que no leen? El poder inmaterial de la literatura, la tradición literaria y el hábito de leer. México: Paidós.

BETTELHEIM, B y ZelanK. (2001) Aprender a leer. Barcelona: Crítica.

CALVINO, I. (1994) Porque leer los clásicos. México: Tusquests.

CASTRO, R. (2002) La intuición de leer, la intención de narrar. México: Paidós 
CUTTS, W. G. (1968) La enseñanza moderna de la lectura. Buenos Aires: Troquel. 